\title{
TRENDS IN SEXUAL PRACTICES OF NEPALESE YOUTH OVER TIME 2006-2016
}

\author{
Dhanendra Veer Shakya*
}

\begin{abstract}
This study attempts to examine trends in incidence of sexual experience, age at first sex, number of life-time sex partners, multiple sex partners in last 12 months, relationship with last sex partner, and use of condom at last sex if last sex partner was other than spouse or nonlive-in-partner among Nepalese youth over time 2006-2016. This study has used 2006, 2011 and 2016 Nepal Demographic and Health Survey data files with weighted cases. Data are analyzed using percentage and frequency tables and statistical tests are carried out using binomial logistic and least square regression models not controlling for variables other than survey years. The findings show that incidences of premarital sex, multiple sex partners in last 12 months and other than spouse or non-live-in-partner as last (most recent) sex partner are increasing over time.
\end{abstract}

Key words: Youth, sexual experience, first sex, last sex, sex partner, spouse, live-in-partner, non-live-in-partner, condom, STIs and odds.

\section{INTRODUCTION}

Sexual activity and behaviour of youth are important issues for any country as it can determine the current and future situation of the country through their health, education and economic status among others. Sex in itself, is not wrong at any age but sex at an early age may harm the mental development of youth in several forms with danger of possible exchange of diseases as young partners may not be aware of diseases that spread through intercourses, and getting pregnant at early age sex is another disaster. Without proper knowledge and aware about sexually transmitted infections (STIs), health of youth could be adversely affected if involved in unsafe sex and at early age. Likewise, early marriage, pregnancy and having a child at early age could end up with school drop-out with further consequences of lost opportunity for economic growth of individuals, specifically for females. Therefore, study of sexual practices of youth and its trend over time is imperative to understand the relevant situation in the country. STIs including Human Immunodeficiency Virus (HIV) mainly affect sexually active young

* Dr. Shakya is an Associate Professor, Central Department of Population Studies, Kirtipur, TU. 
people. Causes of the increased rates of STIs in young people are complex. The main reasons include biological factors, risky sexual behavioural patterns such as early initiation of sex, pre-marital sex, bisexual orientation and multiple sexual partners, transmission dynamics and treatment-seeking behaviour. Research indicated that attitudes, outlooks, norms and beliefs around sexual behaviour determine the intended sexual behaviour of young people. Bridging the gap between knowledge and practice has emerged as a major behaviour change communication challenge to reducing adolescents' vulnerability to STIs and unwanted pregnancies (McManus \& Dhar, 2008).

Adolescent sexual expression is largely taken for granted in Western European countries. The focus of sex education in these countries is not abstinence but the provision of comprehensive information about the biological and emotional aspects of sexual development, relationships, decision-making skills, communication and negotiation. The general expectation is that sexual intercourse will take place within a committed relationship, and those who are having sex will protect themselves and their partners from STIs, if they have access to information and health services (Boonstra, 2007). But the situations in country like Nepal are not such even the government has promoted comprehensive education on sexuality at secondary level and many government and non-government organizations are working in this area providing education, counselling and other services in reproductive health related issues.

The 2016 Nepal Demographic and Health Survey (NDHS) shows that median age at first marriage among women and men aged 25-49 years is 17.9 and 21.7 years respectively. Females marry at early ages than males as 13 percent of women married by age 15 versus only 3 percent of men, 52 percent against 19 percent by age 18 and 71 percent against 38 percent by age 20. Similarly, median age at first sex is 17.9 and 20.5 years respectively among women and men. Likewise, 66 percent women and 72 percent men aged 15-49 years had sexual intercourse within the 12 months preceding the survey and 29 percent of never married men have had sexual intercourse in lifetime. Among youth (15-24), one percent of never married females and 25 percent of males have had premarital sex. Five percent youth females and 3 percent youth males had sexual intercourse before age 15 and 38 percent females and 27 percent males had sexual intercourse before age 18 among aged 18-24 years (MoH, New ERA, \& ICF, 2017).

The 2017 Integrated Biological and Behavioural Surveillance (IBBS) Survey among male labour migrants in western and mid- to farwestern region of Nepal has its findings that 43 percent of male labour 
migrants were married during the adolescent ages with mean age at marriage of 20.3 years. Almost two-third of them (63\%) had first sex before age 20 with mean age at first sex of 19 years and sexual contact with female sex workers was also common among them. Though awareness of HIV/AIDS was prevalent among majority of them, comprehensive knowledge about HIV/AIDS was low (21\%) and exposure to STIs/ HIV/AIDS program was also low (NCASC, 2017).

Studies conducted in African countries reveal that earlier sexual debut have increased STIs risk due to having more sexual partners (Pettifor, 2004 cited in Coleman, 2011). According to research conducted by Harrison et al. (2005 cited in Coleman, 2011), "young men with early sexual debut were 10 times more likely to have had multiple partners reinforcing evidence that early sexual experiences may determine sexual risk behaviours".

\section{OBJECTIVES}

The main objective of this study is to examine the trends in some selected incidences and behaviours related to sexual practices of Nepalese youth over the period 2006-2016. The specific objectives are:

i. To examine trends in incidence of ever having sexual experience, age at first sex and number of life-time sex partners of youth,

ii. To examine trend in having multiple sex partners in last 12 months, and

iii. To examine trends in relationship with last (most recent) sex partner, and condom use in last sex, if partner was other than spouse or nonlive-in-partner.

\section{METHODOLOGY}

This study has used the data files of 2006, 2011 and 2016 Nepal Demographic and Health Surveys to examine the change in incidence of sexual experience, age at first sex, number of life-time sex partners, multiple sex partners in last 12 months, relationship with last sex partner and use of condom at last sex, if last sex partner was other than spouse or non-live-inpartner among Nepalese youth (15-24 years) over time 2006-2016.

The weighted data were used from the survey data files for the purpose of analysis. The weighted sample sizes of youth population were 1,753 males and 4,431 female in 2006; 1,663 males and 5,050 females in 2011; and 1,580 males and 4,849 females in 2016. Similarly, the weighted sample size of youth population who have ever had sexual experience were 643 males and 2,427 females in 2006; 666 males and 2,576 females in 2011; and 666 males and 2,425 females in 2016. 
Data were analyzed using percentage and frequency tables and statistical tests were carried out using binomial logistic and least square regression models not controlling for variables other than survey years. The statistical tests were carried out using logistic and least square regression and outcomes were interpreted with the help of indicators like odds ratio, unstandardized and standardized regression coefficients along with different levels of significance and 95 percent confidence interval as well.

\section{DISCUSSION AND RESULTS}

\section{Sexual Experience of Youth}

Sexual experience of youth has its own importance in the study of their sexual practices in the country like Nepal, where sex before marriage is not taken for granted in society yet, although attitude towards pre-marital sex has been changing as society modernizes. The proportion of youth males who have ever had sexual experience was 41 percent in 2006, which slightly declined by about one percentage point in 2011 to 40 percent, but it increased to 42 percent in 2016 . However, the increase was not statistically significant, i.e. it was 95 percent confident that there was no difference in results and difference was attributed to chance only. The corresponding figures for youth females were 55 percent, 51 percent and 50 percent respectively in the years 2006, 2011 and 2016, which was declining over time (Table 1). This decline among youth females, on the other hand, was significant at $\mathrm{p}<0.001$ level for both the years 2011 and 2016 as their odds was 0.860 and 0.826 times (less) the odds in 2006 to have ever had sexual experience (Appencis Table I), i.e. it was 14 percent and 17 percent less likely to have ever had sexual experience respectively in 2011 and 2016 than in 2006.

Table 1: Distribution (\%) of Youth Population According to Sexual Experience, Nepal, 2006-2016

\begin{tabular}{|l|c|c|c|c|c|c|}
\hline \multirow{2}{*}{ Survey year } & \multicolumn{2}{|c|}{ Male } & \multirow{2}{*}{\begin{tabular}{c} 
Total \\
\cline { 2 - 5 }
\end{tabular}} & Yes & No & \multicolumn{2}{|c|}{ Female } & \multirow{2}{*}{$\begin{array}{c}\text { Total } \\
\text { (n) }\end{array}$} & Yes & No & (n) \\
\hline 2006 & 40.9 & 59.1 & 1,573 & 54.8 & 45.2 & $4,430^{*}$ \\
\hline 2011 & 40.1 & 59.9 & 1,663 & 51.0 & 49.0 & 5,050 \\
\hline 2016 & 42.2 & 57.8 & 1,580 & 50.0 & 50.0 & 4,849 \\
\hline
\end{tabular}

Source: Nepal Demographic and Health Survey, 2006-2016.

Note: *One weighted case of female was missing in 2006. 
If one compares the proportion of youth ever having sexual experience with that of ever married youth, it indicates that many of youth males in Nepal involve in pre-marital sex as proportions of ever married youth males were far below at only 29 percent, 23 percent and 22 percent in the years 2006, 2011 and 2016 respectively (calculated from surveys data files) than that of youth males having sexual experience. But in the case of youth females, proportions ever having sexual experience and ever married were almost same in each of all the survey years. It has suggested that youth males were further postponing their first marriage over time of 20062016 in one hand, while on the other, time of their first sex has not been delayed over the same period, instead it was slightly earlier (Table 1).

\section{Age at First Sex}

Age at first sex is another indicator that may represent situation of sexual practices of youth. Age at first sex of Nepalese youth males was around 18 years and that of females was about 17 years and it was almost at the same level in all the survey years (Table 2). Lower age at first sex of youth females compared to youth males could be attributed to earlier age at marriage of females than males in the country (17.9 and 21.7 respectively for females and males in 2016 (MoH, New ERA, \& ICF, 2017)).

Table 2: Distribution (\%) of Youth Population According to Age at First Sex, Nepal, 2006-2016

\begin{tabular}{|c|c|c|c|c|c|c|c|}
\hline \multirow{2}{*}{$\begin{array}{l}\text { Survey } \\
\text { year }\end{array}$} & \multicolumn{5}{|c|}{ Age at first sex } & \multirow[t]{2}{*}{ Mean } & \multirow{2}{*}{$\begin{array}{l}\text { Total } \\
\text { (n)* }\end{array}$} \\
\hline & $<15$ & $15-16$ & 17-18 & 19-20 & $>20$ & & \\
\hline \multicolumn{8}{|l|}{2006} \\
\hline Male & 9.7 & 26.2 & 31.5 & 18.8 & 13.8 & 17.6 & 643 \\
\hline Female & 13.9 & 39.7 & 29.6 & 12.6 & 4.1 & 16.6 & 2,385 \\
\hline \multicolumn{8}{|l|}{2011} \\
\hline Male & 7.6 & 25.7 & 31.3 & 22.5 & 12.9 & 17.7 & 665 \\
\hline Female & 13.9 & 32.2 & 28.3 & 16.8 & 8.8 & 17.0 & 2,545 \\
\hline \multicolumn{8}{|l|}{2016} \\
\hline Male & 7.1 & 28.3 & 33.3 & 20.6 & 10.7 & 17.6 & 666 \\
\hline Female & 10.2 & 32.7 & 32.2 & 16.7 & 8.2 & 17.1 & 2,416 \\
\hline
\end{tabular}

Source: Nepal Demographic and Health Survey, 2006-2016.

Note: *Excluded inconsistent and missing cases.

The proportion of Nepalese youth females with age at first sex at below 15 years and 15-16 years was declined from 14 percent to 10 percent and 40 percent to 33 percent respectively during the period of 2006-2016 
but it was increased at $17-18,19-20$ and above 20 years from 30 percent to 32 percent, 13 percent to 17 percent and 4 percent to 8 percent respectively over the same period. The decline in proportion at below 17 years could be attributed to decreasing girl's child marriage and increasing overall age at marriage of females over time. The change in age at first sex of youth females over the period was gradual but it was statistically significant at $\mathrm{p}<0.001$ level (Appendix Table II), i.e. it is 95 percent confident that there was difference in results and difference is not attributed to chance.

The proportion of youth males with age at first sex at below 15 years was declined over time from 10 percent in 2006 to 7 percent in 2016 on one hand, while on the other, the proportion at above 20 years was also found declined from 14 percent to 11 percent during the same period. But the proportion with age at first sex at 15-20 years was increased over time. The decline in proportion at below 15 years, in this case, could also be attributed to decreasing boy's child marriage over time, while decline in proportion at above 20 years might be due to shifting in time of first sex of youth males little earlier as found in previous sub-section of sexual experience. However, the change in age at first sex of Nepalese youth males over time was not found statistically significant at $p<0.05$ level, i.e. it is 95 percent confident that there was no difference in results and difference was attributed to chance only.

\section{Life-time Sex Partners}

Individuals who have multiple sexual partners increase their risk of contracting STI as each new relationship introduces another pathway for STI transmission. For the individuals with multiple partners, their risk of acquiring STIs is directly related to the number of sexual partners they have over time. Multiple sex partners and STIs have a strong correlation. It boosts the chances of contracting STI, as from one sexual partner, it is transmitted to the next one and this chain continues. Multiple sexual partnerships and its consequence could be metaphorically described as something very similar to that of a water fall.

The number of life-time sex partners could also indicate youth's sexual behaviour. The proportion of youth males having only a single sex partner as number of life-time sex partners declined from 67 percent in 2006 to 52 percent in 2016, while it was increased from 15 percent to 21 percent, 7 percent to 12 percent, 4 percent to 5 percent, and 7 percent to 10 percent respectively for having number of life-time sex partners two, three, four and more than four over the same period. The average number of life- 
time sex partners of Nepalese youth males was 2.1 in 2006, which increased to around 2.6 in both the years 2011 and 2016 (Table 3). However, the increase in number of life-time sex partners of youth males over time was not found statistically significant, i.e. it is 95 percent confident that there was no difference in results and difference was attributed to chance only. As for youth females, the average number of life-time sex partners was almost only one in all the survey years.

Table 3: Distribution (\%) of Youth Population According to Number of Life-time Sex Partners, Nepal, 2006-2016

\begin{tabular}{|c|c|c|c|c|c|c|c|}
\hline \multirow{2}{*}{$\begin{array}{l}\text { Survey } \\
\text { year }\end{array}$} & \multicolumn{5}{|c|}{$\begin{array}{c}\text { Number of life-time sex } \\
\text { partners }\end{array}$} & \multirow{2}{*}{$\begin{array}{c}\text { Mean life- } \\
\text { time sex } \\
\text { partners }\end{array}$} & \multirow[t]{2}{*}{ Total (n) } \\
\hline & 1 & 2 & 3 & 4 & $>4$ & & \\
\hline \multicolumn{8}{|l|}{2006} \\
\hline Male & 67.4 & 14.9 & 6.9 & 4.0 & 6.8 & 2.06 & 643 \\
\hline \multicolumn{8}{|l|}{ Female } \\
\hline \multicolumn{8}{|l|}{2011} \\
\hline Male & 59.7 & 18.2 & 8.4 & 3.8 & 9.8 & 2.63 & 666 \\
\hline Female & 98.4 & 1.5 & 0.1 & - & 0.0 & 1.03 & 2,576 \\
\hline \multicolumn{8}{|l|}{2016} \\
\hline Male & 51.5 & 21.4 & 12.3 & 4.7 & 10.1 & 2.55 & 666 \\
\hline Female & 98.7 & 1.2 & - & 0.0 & 0.1 & 1.04 & 2,425 \\
\hline
\end{tabular}

Sources: Nepal Demographic and Health Survey, 2006-2016.

\section{Multiple Sex Partners in Last 12 Months}

Individuals who have multiple sexual partners are associated with different risks. An individual's risk cannot be calculated solely on the basis of his or her behaviour, but could only be assessed in light of their partner's behaviour. As such an indicator of multiple sex partners in last 12 months was one of the major indicators to examine the sexual behaviour of any person as it reveals the extent of sexual activity and risky sexual practices. The proportion of Nepalese youth males with multiple sex partners in last 12 months increased by almost double from 5 percent in 2006 to more than 9 percent in 2011 and to about 10 percent in 2016 (Table 4), whereas the corresponding figure for youth females was negligible with meagre 0.1 percent and it is almost same in all the survey years, in fact, even declined in the year 2016. The increase in proportion of youth males having multiple sex partners in last 12 months indicates that they might be engaging in more risky sexual practices and they were not giving importance towards single faithful sex partner or today's youth males are not much aware of or did not care about it. 
Table 4: Distribution (\%) of Youth Population According to Multiple Sex Partners in Last 12 Months, Nepal, 2006-2016

\begin{tabular}{|l|c|c|c|c|c|c|}
\hline \multirow{2}{*}{ Survey year } & \multicolumn{2}{|c|}{ Male } & \multirow{2}{*}{ Total } & \multicolumn{2}{c|}{ Female } & Total \\
\cline { 2 - 3 } & Yes & No & $(\mathrm{n})$ & Yes & No & $(\mathrm{n})$ \\
\hline 2006 & 5.2 & 94.8 & 643 & 0.1 & 99.9 & 2,427 \\
\hline 2011 & 9.4 & 90.6 & 666 & 0.1 & 99.9 & 2,576 \\
\hline 2016 & 9.5 & 90.5 & 666 & - & 100.0 & 2,425 \\
\hline
\end{tabular}

Source: Nepal Demographic and Health Survey, 2006-2016.

The statistical test shows that youth males in 2016 and 2011 were 1.913 and 1.897 times more likely to have multiple sex partners in last 12 months respectively than in 2006, both of which were significant at $\mathrm{p}<0.01$ level (Annex Table I), i.e. it was 95 percent confident that there was difference in results and difference was not attributed to chance.

\section{Relationship with Last (most recent) Sex Partner}

For the purpose of distinguishing last (most recent) sex partner as regular and non-regular and also considering the number of cases, it was categorized in this study into two categories viz. spouse or live-in-partner as regular partner and other than spouse or non-live-in-partner as nonregular partner. The data shows that there was drastic change in proportion of youth males whose last or most recent sex partner was other than spouse or non-live-in-partner over time. It was only 17 percent in 2006, which increased to about 35 percent in 2011 and further increased to around 40 percent in 2016, an increase by almost 23 percentage points over 10 years period (Table 5).

Table 5: Distribution (\%) of youth population according to relationship with last (most recent) sex partner, Nepal, 2006-2016

\begin{tabular}{|l|r|r|r|}
\hline \multirow{2}{*}{$\begin{array}{l}\text { Relationship with last (most recent) } \\
\text { partner }\end{array}$} & \multicolumn{4}{|c|}{ Survey year } \\
\cline { 2 - 4 } & $\mathbf{2 0 0 6}$ & $\mathbf{2 0 1 1}$ & $\mathbf{2 0 1 6}$ \\
\hline Male & 82.8 & 65.4 & 60.5 \\
\hline Spouse/live-in-partner & 17.2 & 34.6 & 39.5 \\
\hline Other than spouse/non-live-in-partner & 542 & 569 & 567 \\
\hline Total (n)* & \multicolumn{5}{|l}{} \\
\hline Female & 99.8 & 99.5 & 99.5 \\
\hline Spouse/live-in-partner & 0.2 & 0.5 & 0.5 \\
\hline Other than spouse/non-live-in-partner & 2,225 & 2,266 & 2,046 \\
\hline Total (n)*
\end{tabular}

Sources: Nepal Demographic and Health Survey, 2006-2016.

Note: *Excluded missing cases. 
It reveals that incidence of sexual relation of youth males before marriage and outside marital union was in increasing trend. Statistical test has also indicated that youth males in 2016 and 2011 were more likely to have last sex partner as other than spouse or non-live-in-partner compared to that in 2006 with odds ratios of $3.142(\mathrm{p}<0.001)$ and $2.550(\mathrm{p}<0.001)$ respectively with statistically significant (Annex Table I). But the same could not be said to youth females as their proportion increased only by very small magnitude of 0.3 percentage point over the same period and found statistically not significant as well.

\section{Use of Condom with Last Sex Partner Other than Spouse/Non-live-in- Partner}

If husband had other partners, wife had a higher risk of HIV infection if husbands did not use a condom the last time they had sex with partners other than their wives. The low frequency of condom use within marriage and the high frequency of extramarital sex among men have suggested that a substantial proportion of married people will be exposed to STI infection through unprotected sexual intercourse with their STIinfected spouse (Amornkul et al., 2009). There was a significant relationship between number of partners and condom use during last sexual episode. Persons having sex with multiple partners weremuch less likely to have used a condom during their last sexual episode compared to those who did not have multiple partners (Nnedu, McCorvey, Campbell-Forrester, Chang, Salihu, \& Jolly, 2008). Hence, use or non-use of condom during sex with non-regular partner was an important indicator to measure extent of risky sexual behaviour of any person. The data shows that the proportion of youth males using condom at last sex, if last sex partner was other than wife or non-live-in-partner, declined from 77 percent in 2006 to 73 percent in 2011 and 69 percent in 2016 (Table 6). Statistical test shows that there was 0.653 and 0.803 times less likely to use condom at last sex, if last sex partner was other than wife or non-live-in-partner, in 2016 and 2011 respectively than in 2006 (Appendix Table I). The declining trend of condom use at last sex with non-regular partner could make youth males at more risk of contracting sexually transmitted infections. However, the result was not found significant at level of significance $\mathrm{p}<0.05$. 
Table 6: Distribution (\%) of Youth Population According to Condom Use in last (most recent) Sex if Partner was Other than Spouse/Non-live-in Partner, Nepal, (2006-2016)

\begin{tabular}{|l|c|c|c|c|c|c|}
\hline \multirow{2}{*}{ Survey year } & \multicolumn{2}{|c|}{ Male } & \multirow{2}{*}{$\begin{array}{c}\text { Total } \\
\end{array}$} & Yes & No & \multicolumn{2}{|c|}{ Female } & Total \\
& 77.0 & 23.0 & 93 & 24.8 & 75.2 & 4 \\
\hline 2006 & 72.8 & 27.2 & 197 & 55.8 & 44.2 & 12 \\
\hline 2011 & 68.6 & 31.4 & 224 & 64.6 & 35.4 & 10 \\
\hline 2016 & &
\end{tabular}

Source: Nepal Demographic and Health Survey, 2006-2016 Data Files.

The situation was just opposite in the case of youth females, as the proportion of youth females using condom at last sex, if last sex partner was other than husband or non-live-in-partner, increased from 25 percent in 2006 to 56 percent in 2011 and further increased to 65 percent in 2016 indicating 5.530 and 3.834 times more likely to use condom at last sex, if last sex partner was other than husband or non-live-in-partner, in 2016 and 2011 respectively than in 2006 (Appendix Table I). In this case also, however, the result was not found significant statistically.

\section{CONCLUSION}

There is only a meagre change in the proportion of Nepalese youth males who have ever had sexual experience over time 2006-2016, but there was significant decline among youth females ever having sexual experience. Age at first sex of youth males was almost at constant level of less than 18 years over the same period, but for youth females it was gradually increasing with statistically significant. The average number of life-time sex partners of youth males also increased from a little over 2 to slightly less than 3 on one hand, while on the other hand, the proportion having only a single sex partner as number of life-time sex partners declined from 67 percent to 52 percent over the same period. The proportion of youth males with multiple sex partners in last 12 months also increased by almost double from 5 percent to 10 percent with statistically significant. There was also drastic change in proportion of youth males whose last sex partner was other than wife or non-live-in-partner from only 17 percent to 40 percent. The proportion of youth males using condom at last sex, if last sex partner was other than wife or non-live-in-partner, declined from 77 percent to 69 percent. But the situation was just opposite in the case of youth females, which increased from 25 percent to 65 percent. 


\section{Appendix}

Table I: Use of logistic regression analysis in change in some selected variables among Nepalese youth over the time period of 2006-16

\begin{tabular}{|l|c|c|c|}
\hline \multirow{2}{*}{ Selected variables } & \multicolumn{3}{|c|}{ Odds ratio (95\% CI) } \\
\cline { 2 - 4 } & 2006 & 2011 & 2016 \\
\cline { 2 - 4 } Sexual experience (yes) & \multicolumn{3}{|c|}{ Survey year } \\
\hline Male & Ref. & $0.967(0.841-1.113)$ & $1.054(0.915-1.215)$ \\
\hline Female & Ref. & $0.860(0.793-0.932)^{* * *}$ & $0.826(0.761-0.896)^{* * *}$ \\
\hline Multiple sex partners in last 12 month (yes) \\
\hline Male & Ref. & $1.897(1.228-2.931)^{* *}$ & $1.913(1.239-2.954)^{* *}$ \\
\hline Female & Ref. & $0.612(0.083-4.503)$ & $0.000(0.000-n a)$ \\
\hline Relationship with last sex partner (other than spouse/non-live-in-partner) \\
\hline Male & Ref. & $2.550(1.923-3.380)^{* * *}$ & $3.142(2.376-4.155)^{* * *}$ \\
\hline Female & Ref. & $3.135(0.972-10.116)$ & $3.016(0.915-9.939)$ \\
\hline Condom use in last sex if partner was other than spouse/non-live-in-partner (yes) \\
\hline Male & Ref. & $0.803(0.452-1.427)$ & $0.653(0.374-1.142)$ \\
\hline Female & Ref. & $3.834(0.277-53.146)$ & $5.530(0.376-81.382)$ \\
\hline
\end{tabular}

Source: Nepal Demographic and Health Survey, 2006-2016 Data Files. $* \mathrm{p} \leq 0.05,{ }^{*} \mathrm{p} \leq 0.01$ and $* * * \mathrm{p} \leq 0.001$.

Table II: Use of Regression Analysis in Change in age at First Sex and Number of Life-Time Sex Partners Among Nepalese Youth Over the Time Period of 2006-16

\begin{tabular}{|l|c|c|c|}
\hline \multirow{2}{*}{ Selected variables } & \multicolumn{3}{|c|}{ Regression coefficient $\beta$} \\
\cline { 2 - 4 } & Unstandardized & Standardized & $(95 \% \mathrm{CI})$ \\
\hline Age at first sex & -0.024 & -0.008 & $((-0.157)-0.108)$ \\
\hline Male & 0.256 & 0.091 & $(0.192-0.321)^{* * *}$ \\
\hline Female & 0.241 & 0.040 & $((-0.027)-0.508)$ \\
\hline Number of life-time sex partners \\
\hline Male & 0.005 & 0.003 & $((-0.037)-0.046)$ \\
\hline Female
\end{tabular}

Source: Nepal Demographic and Health Survey, 2006-2016 Data Files. $* \mathrm{p} \leq 0.05, * * \mathrm{p} \leq 0.01$ and $* * * \mathrm{p} \leq 0.001$. 


\section{REFERENCES}

Amornkul, P.N., Vandenhoudt, H., Nasokho, P., Odhiambo, F., Mwaengo, D., Hightower, A., Buvé, A., Misore, A., Vulule, J., Vitek, C., Glynn, J., Greenberg, A., Slutsker, L., \& De Cock, K.M. (2009). HIV prevalence and associated risk factors among individuals aged 13-34 years in rural western Kenya, 4(7), 6470.

Boonstra, H.D. (2007). Young people need help in preventing pregnancy and HIV; How will the world respond? Guttmacher Policy Review, 10(3), 2-7, 14.

Coleman, M. (2011). The importance of delayed sexual debut in lowering the risk of HIV/AIDS infection. Retrieved Jan 31, 2012 from http:// www.marinacoleman.com/the-importance-of-delayed-sexualdebut-in-lowering-the-risk-of-hivaids-infection/.

McManus, A., \& Dhar, L. (2008). Study of knowledge, perception and attitude of adolescent girls towards STIs/HIV, safer sex and sex education: A cross sectional survey of urban adolescent school girls in South Delhi, India. BMC Women's Health, 8(12). Retrieved Jan 17, 2012 from http://www.biomedcentral.com/1472-6874/8/12.

Ministry of Health (MoH) [Nepal], New ERA, \& ICF. (2017). Nepal demographic and health survey 2016. Kathmandu: $\mathrm{MoH}$.

- - - New ERA, \& ICF. (2017). Data files of Nepal demographic and health survey 2006, 2011, 2016. Kathmandu: MoH.

National Centre for AIDS and STD Control (NCASC). (2017). Integrated biological and behavioural surveillance (IBBS) survey among male labour migrants in western and mid-to far-western region of Nepal, Round VI-2017. Kathmandu: NCASC.

Nnedu, O.N., McCorvey, S., Campbell-Forrester, S., Chang, J., Salihu, H.M., \& Jolly, P.E. (2008). Factors influencing condom use among sexually transmitted infection clinic patients in Montego Bay, Jamaica. The Open Reproductive Science Journal, 1, 45-50. 